\title{
Dietary Interventions in Liver Diseases: Focus on MAFLD and Cirrhosis
}

\author{
Élise Vuille-Lessard ${ }^{1} \cdot$ Naomi Lange $^{1,2} \cdot$ Carlotta Riebensahm $^{2,3} \cdot$ Jean-François Dufour ${ }^{1,4} \cdot$ Annalisa Berzigotti $^{1,4}$ (D)
}

Accepted: 25 March 2021 / Published online: 19 April 2021

(C) The Author(s) 2021

\begin{abstract}
Purpose of Review Dietary interventions (DI) aimed at improving overweight and metabolic abnormalities in metabolic dysfunction-associated fatty liver disease (MAFLD) and at reducing malnutrition and sarcopenia in cirrhosis should become part of routine care in hepatology. This review focuses on recent advances in this field.

Recent Findings In patients with MAFLD, a gradual reduction, respectively, of 7-10\% of body weight if overweight or of 3-5\% if lean, obtained by moderately reducing caloric intake, is effective to improve liver disease. Intermittent energy restriction might be an alternative to continuous energy restriction with higher adherence. Qualitative dietary adjustments should include increased intake of unprocessed foods including fruits and vegetables, whole grains, fiber, and unsaturated fatty acids (FAs), for example, through a Mediterranean diet. Refined carbohydrates (CHOs), saturated FA (SFAs), red meat, and processed meat should be limited. DI studies in HIV-infected subjects with MAFLD are very limited, and this is a field for future research. In patients with cirrhosis, DI should aim at correcting malnutrition and improving skeletal muscle mass. Daily diet contents should aim at achieving 30-35 kcal $/ \mathrm{kg}$ of body weight, including $1.2-1.5 \mathrm{~g} / \mathrm{kg}$ proteins, and oral or enteral supplementation might be used in patients unable to achieve these targets. In some studies, branched-chain amino acids (BCAAs) proved to be effective in improving muscle mass and were associated with a lower risk of hepatic encephalopathy. Obesity requires adjustment of the above-mentioned targets, and its management is challenging. Studies looking at the efficacy of DI recommended by the existing guidelines on clinical endpoints are a field for future research.

Summary Dietary interventions are able to improve MAFLD and show potential to reduce complications in liver disease. Despite its key importance, there are many barriers limiting the implementation of DI in patients with chronic liver disease. Patients' empowerment is crucial and should be the focus of specific educational programs. In addition, liver clinics would benefit from multidisciplinary teams involving experts in nutrition, physical exercise, primary care physicians, and psychologists when needed.
\end{abstract}

Keywords Steatosis $\cdot$ NASH $\cdot$ Fibrosis $\cdot$ HIV $\cdot$ Portal hypertension $\cdot$ BCAAs

This article is part of the Topical Collection on Nutrition in Patients with Chronic Liver Disease

Élise Vuille-Lessard and Naomi Lange contributed equally and share first authorship

Annalisa Berzigotti

Annalisa.berzigotti@insel.ch

1 University Clinic for Visceral Surgery and Medicine, Bern University Hospital, University of Bern, MEM F807, Murtenstrasse 35, CH - 3008 Berne, Switzerland

2 Graduate School for Health Sciences (GHS), University of Bern, Bern, Switzerland

3 Department of Infectious Diseases, Bern University Hospital, University of Bern, Bern, Switzerland

4 Hepatology, Department of Biomedical Research, University of Bern, Bern, Switzerland

\section{Introduction}

The liver is a key organ for the metabolism of proteins, fats, and carbohydrates (CHOs). Not surprisingly, liver health is strictly related to metabolic health. Fatty liver disease has become highly prevalent in the general population, mostly driven by excessive food/calorie intake along with sedentary behavior as well as genetic and environmental factors (e.g., exposure to chemicals leading to alterations of the gut microbiome [1]), leading to obesity and metabolic dysfunction. Among the genetic factors modulating the risk of MAFLD and its progression to cirrhosis and hepatocellular carcinoma, confirmed associations include single-nucleotide polymorphisms in patatin-like phospholipase domain-containing 3 (PNPLA3), transmembrane 6 superfamily member 2 (TM6SF2), glucokinase 
regulatory protein gene (GCKR), and HSD17B13, encoding for a retinol dehydrogenase $[2 \bullet]$.

MAFLD is also more frequent in people living with HIV (PLWH) [3-5], likely due to the inflammation and bacterial translocation related to HIV infection per se, as well as lifelong antiretroviral therapy (ART) [6, 7]. Although older drugs most likely to cause lipodystrophy are not used anymore, newer antiretroviral drugs, such as dolutegravir and tenofovir alafenamide (TAF), remain associated with metabolic side effects and weight gain [8-10] as classic metabolic risk factors for MAFLD [11, 12].

On the other hand, protein-calorie malnutrition is frequent in patients with liver disease in the cirrhotic stage due to several mechanisms. Cirrhosis implies impaired hepatic and skeletal muscle glycogen synthesis and storage, increased protein catabolism, and increased lipolysis. In addition, portal hypertension leads to malabsorption through impaired gut motility, dysbiosis and mucosal changes, and decompensated disease. The latter often features systemic inflammation and ascites, conditions requiring increased caloric intake which cannot be easily matched due to loss of appetite, resulting in severe malnutrition and sarcopenia. Genetic and environmental factors in this specific setting have not been investigated so far.

This review will provide an update on the existing dietary interventions to improve the nutritional status of patients with chronic liver disease, focusing on the two most prevalent conditions, namely, metabolic dysfunction-associated liver disease (MAFLD)/metabolic dysfunction-associated steatohepatitis (MASH) (previously termed more generically non-alcoholic fatty liver disease, NAFLD, and non-alcoholic steatohepatitis, NASH) and cirrhosis.

\section{Nutritional Interventions in MAFLD/MASH}

While no pharmacological therapy is approved for the treatment of MAFLD, several international guidelines, including HIV guidelines, advocate the use of lifestyle interventions, often including dietary interventions (DI) [13-15], due to the direct link between MAFLD and comorbid metabolic disorders such as obesity and diabetes mellitus type 2 , in which such interventions have been proven effective. It should be noted that genetic and environmental factors, which are known to modulate comorbid metabolic conditions, may also mediate the individual response to DI and lifestyle interventions in general. Future studies are needed to further investigate these possible effects.

Interventional studies on nutrition in MAFLD cover a broad spectrum of dietary measures (Table 1). The main categories include energy restriction through changes in dietary composition and certain patterns of food intake such as fasting, as well as changes in the composition of macronutrients and micronutrients, including dietary supplements and specific foods. Many studies use a combination of these measures, making direct comparison of the results challenging. Fig. 1a summarizes the suggested DI for MAFLD and associated comorbid conditions and areas of uncertainty.

\section{Energy/Calorie Restriction}

Several trials have been able to demonstrate the beneficial effects of weight loss on liver enzymes as well as histological outcomes such as steatosis and inflammation, although the evidence regarding fibrosis is less conclusive [34, 35•]. Besides surgical interventions or pharmacotherapy, weight loss can be achieved through dietary measures limiting energy intake, sometimes in combination with increased physical exercise (PE), which may also include increased physical activities of daily living or medications [36, 37]. Generally, DI using caloric restriction can be classified into continuous and intermittent energy restriction, although such a strict distinction is not always possible.

A major concern with diets that include energy restriction or other comprehensive dietary adjustments is the lack of sustainability of weight loss. A brief report of the observational and longitudinal TARGET-NASH cohort study recently demonstrated that while around one third of over 2000 overweight or obese individuals with MAFLD achieved a weight reduction of $\geq 5 \%$ in standard clinical care, only $25 \%$ of these patients were able to sustain this over a median follow-up of 39 months [38]. Factors that negatively influence the sustainability of DI and other lifestyle interventions include psychological, socioeconomic, physiologic, and genetic factors. A thorough discussion of these factors is beyond the scope of this review, but these have been excellently reviewed elsewhere [39].

\section{Continuous Energy Restriction: Hypocaloric Diet}

A hypocaloric diet is a form of continuous energy restriction, usually involving a daily calorie deficit of 500-1000 kcal. In the literature, hypocaloric diets are explored with or without changes in macronutrient composition. In a randomized controlled trial (RCT), an intervention that combined hypocaloric diet and PE in obese patients with type 2 diabetes mellitus showed a reduction of steatosis by nearly $80 \%$ in patients who lost $\geq 10 \%$ of body weight compared to $14 \%$ in those with less body weight loss [40]. In a 48-week lifestyle intervention that included moderate calorie restriction with reduced fat intake as well as coaching on behavior and PE, significant histological improvements in steatosis, parenchymal inflammation, ballooning injury, and overall NAFLD activity score, but not in the fibrosis stage, were observed in patients who achieved the weight loss goal of $\geq 7 \%$ of body weight compared to controls [41]. In a more recent trial from Cuba, $81 \%$ of patients with fibrosis at baseline who followed a 


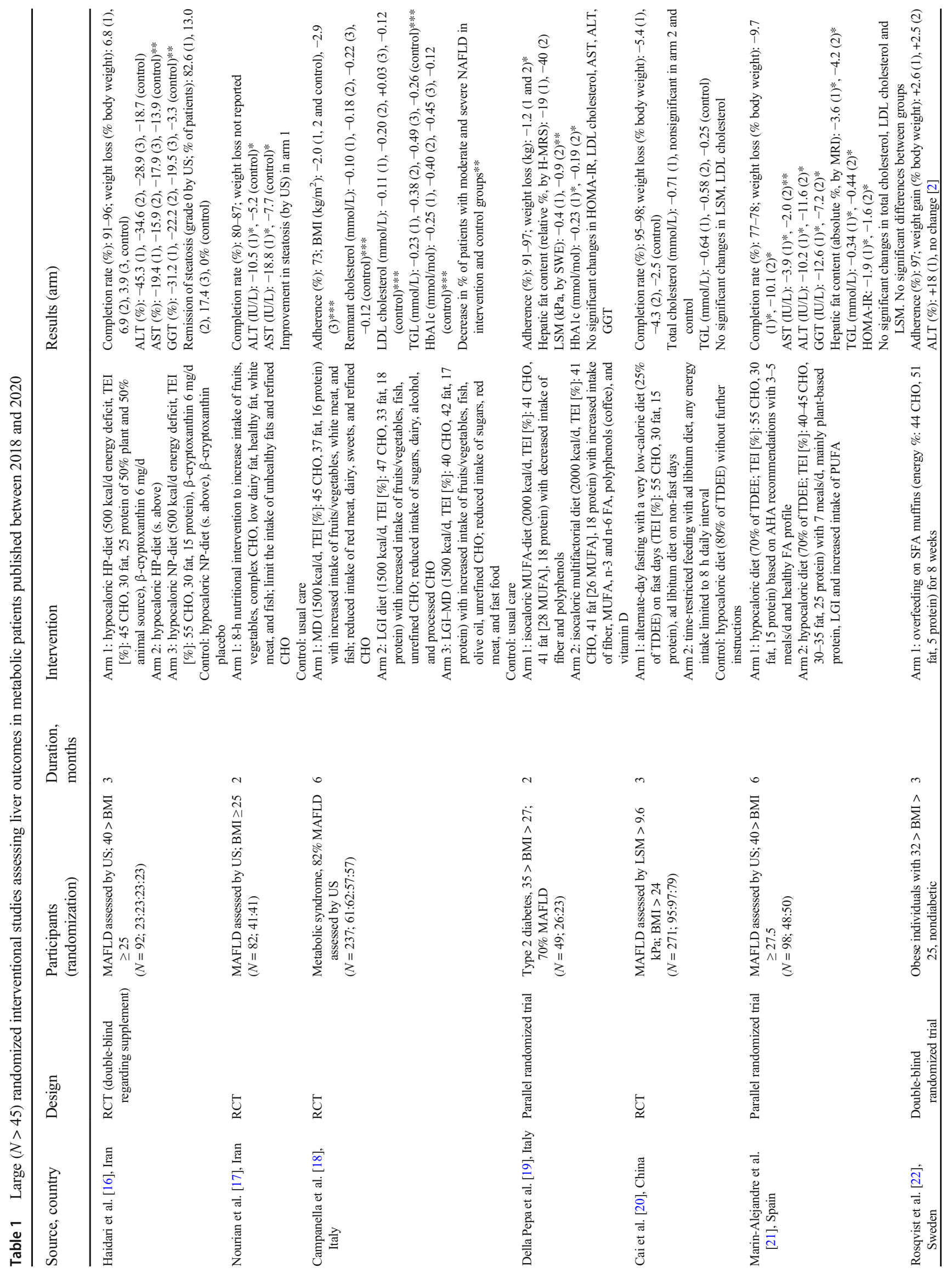




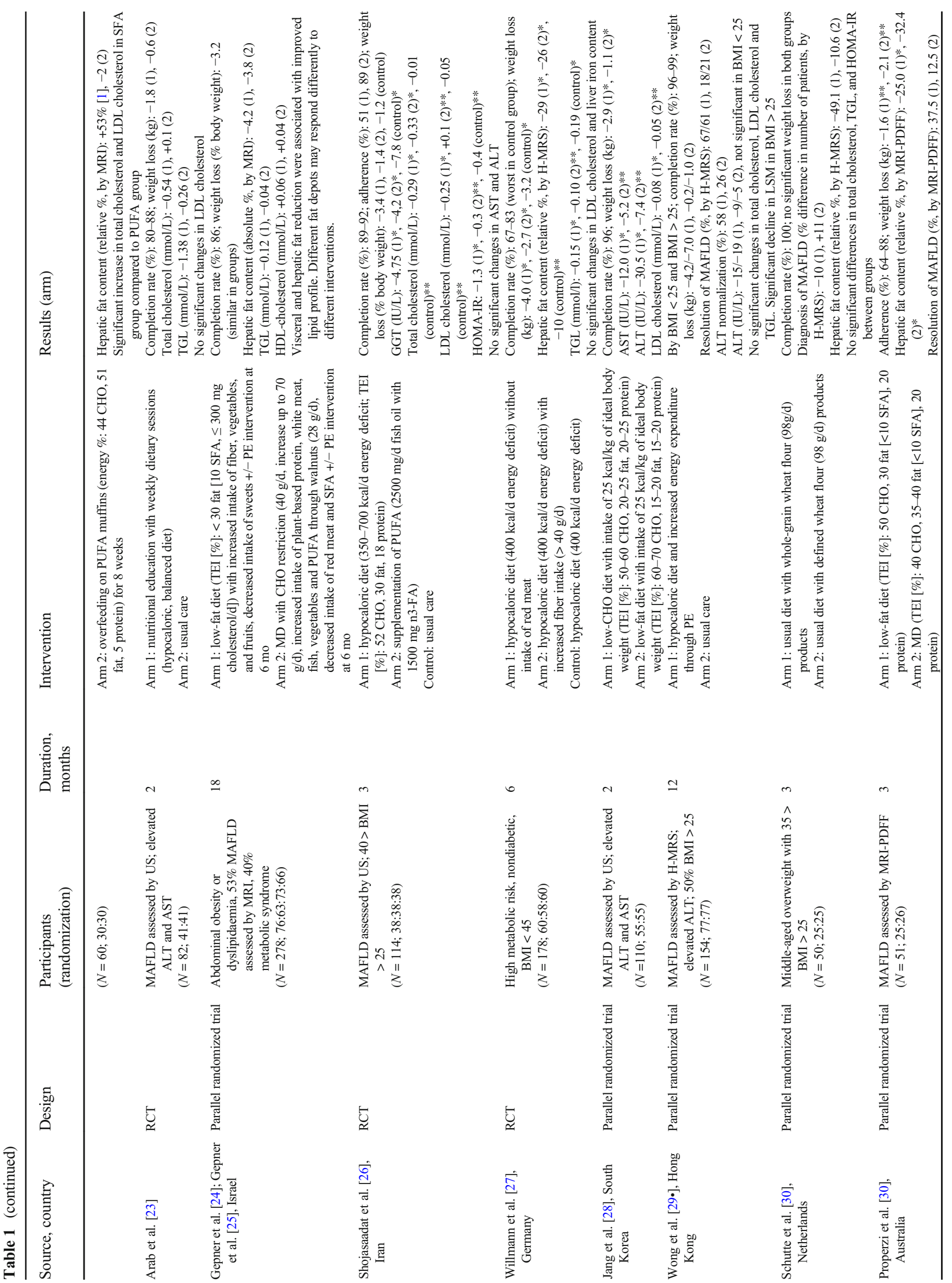




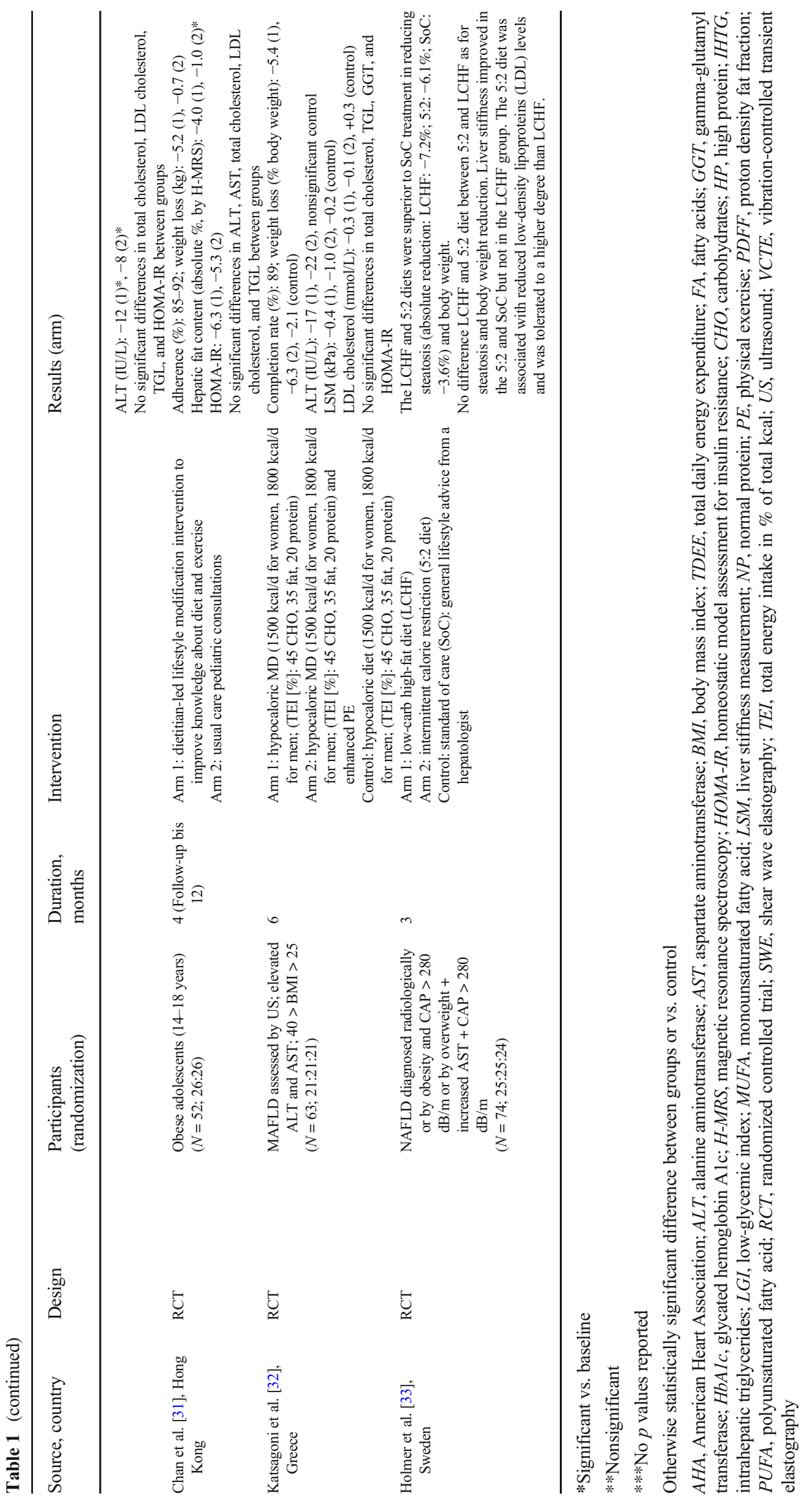


a

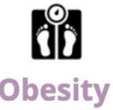

- Hypocaloric diet combined with increased physical activity, as well as intermittent energy restriction, lead to weight loss

- Weight loss of 7-10\% for obese and 3-5\% for

lean individuals should be attempted

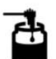

Impaired glucose homeostasis or diabetes

- Medically supervised ketogenic diet may be feasible and appears beneficial with respect to fasting glucose and $\mathrm{HbA} 1 \mathrm{C}$

- The combination of various dietary interventions improves insulin sensitivity

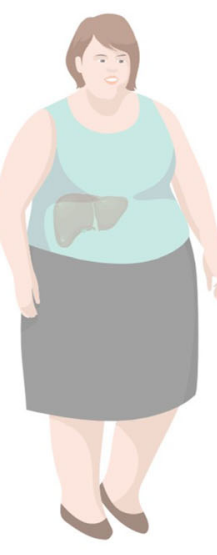

b

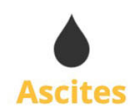

- Reduced with oral supplementation and reduced post-operatively with parenteral supplementation

- Reduced with late evening snack (BCAA-related?)

- Reduced with BCAAs post HCC treatment

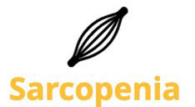

- Increase in muscle mass with oral supplementation

- Increase in muscle mass and strength with BCAAs

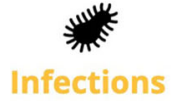

- Reduced incidence with oral

supplementation

- Reduced post-operatively with parenteral supplementation

Fig. 1 a Suggested dietary interventions for MAFLD and associated comorbid conditions and areas of uncertainties. b Reported effects of nutritional interventions on clinical endpoints in cirrhosis and areas of uncertainties. Abbreviations used: MAFLD, metabolic associated fatty liver disease; MD, Mediterranean diet; MUFAs, monounsaturated fatty

\section{Cardiovascular risk factors}

- Improved with the consumption of a well-balanced diet rich in fibers (e.g. Mediterranean diet), with an associated survival benefit

\section{2}

Histological components of MAFLD

-Weight loss leads to reduced steatosis and inflammation, and possibly fibrosis

- Coffee consumption may prevent fibrosis

- Increased intake of poly-unsaturated FAs (including omega-3 and -6) and mono-unsaturated FAs with reduction of saturated FAs may reduce steatosis - Favoring proteins (especially plant-based) over carbohydrates and limiting intake of free sugars improve steatosis

\author{
(3) \\ Areas of \\ uncertainty \\ - Dietary interventions with \\ definite beneficial effects on \\ fibrosis \\ - Optimal combinations of \\ dietary interventions (also \\ taking into account \\ comorbidities) \\ - Lifestyle interventions with \\ maximal adherence in a real \\ life setting \\ - Influence of genetic and \\ environmental factors on \\ individual response to dietary \\ interventions
}

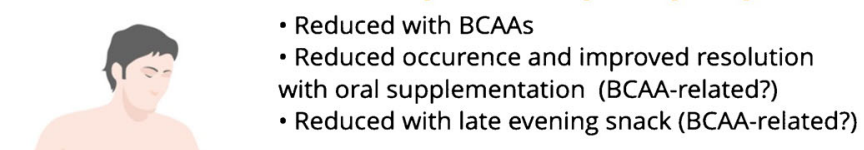

\section{$\bullet$ \\ Hepatocellular carcinoma}

- Reduced post locoregional therapy recurrence with BCAAs

- Improved post treatment liver function with BCAAS

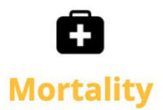

- Survival benefit with oral and parenteral supplementation

- No clear survival benefit with BCAAs (except

decreased long-term mortality after HCC therapy)

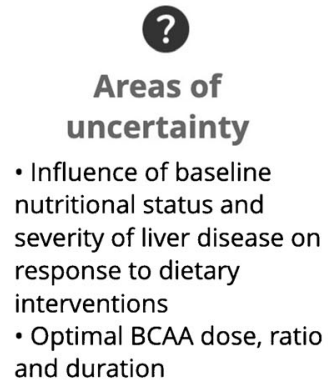

and duration hypocaloric low-fat diet and lost $\geq 10 \%$ of body weight had a reduction of at least 1 point in the histological fibrosis score [42]. Two studies suggested that lean patients may also experience MAFLD remission after the loss of 3-5\% of body weight through a hypocaloric diet [29•, 43].

\section{Intermittent Energy Restriction: Intermittent Fasting and Time-Restricted Feeding}

Previous research has shown a significant increase in hepatic steatosis when a hypercaloric diet was consumed with high meal frequency compared to consumption of the same diet acids; PUFAs, polyunsaturated fatty acids; SFAs, saturated fatty acids; BCAAs, branched-chain amino acids; LES, late evening snack; HCC, hepatocellular carcinoma; ONS, oral nutritional supplementation; PNS, parenteral nutritional supplementation

through larger meals [44]. Intermittent energy restriction has been proposed as an alternative to continuous energy restriction. Most interventions can be classified into either intermittent fasting, which implies a $>60 \%$ energy restriction on $>2$ days per week, or time-restricted feeding, where the daily food intake is limited to $8-10 \mathrm{~h}$ [45]. In a Malaysian study, 8 weeks of intermittent fasting with alternate-day calorie restriction resulted in the reduction of body weight and liver enzymes as well as liver steatosis and stiffness compared to a habitual diet [46]. A larger Chinese RCT randomized 271 MAFLD patients to undergo intermittent fasting, time-restricted feeding, or no intervention [20]. Both intermittent fasting and 
time-restricted feeding induced significant weight loss of $5.4 \%$ and $4.3 \%$, respectively, while LDL, fasting insulin, and liver stiffness did not differ significantly between groups. Finally, satisfactory dietary adherence was reported in both trials, which may indicate a possible advantage with regard to sustainability compared to a hypocaloric diet.

\section{Macronutrient Composition}

Several trials have assessed the possible effects of macronutrient composition on MAFLD, but the overlap of different interventions and effects limits the interpretation of results.

\section{Fat Content}

Several observational studies have demonstrated an association between MAFLD and higher intake of SFAs as well as decreased intake of polyunsaturated fatty acids (PUFAs), independently of total energy intake, suggesting that favoring PUFAs over SFAs in the diet may improve MAFLD [47]. In an RCT from Finland among 38 obese individuals, intrahepatic triglycerides rose by $55 \%$ in those overfed with SFAs, while the increase was $15 \%$ and $33 \%$ in the unsaturated FA and CHO groups, respectively [48]. In a Swedish doubleblind RCT, despite similar weight gain in both groups, overweight subjects showed a $53 \%$ relative increase in intrahepatic fat after overeating SFAs from palm oil compared to a $2 \%$ decrease with omega-6 PUFAs from sunflower oil [22]. This effect was more pronounced than what had been seen for healthy lean subjects in a previous study [49]. An isocaloric diet containing monounsaturated fatty acids (MUFAs) significantly decreased liver fat fraction by MRI and improved insulin sensitivity compared to a regular or fiber-rich diet over 12 weeks [50].

This has inspired several trials on supplementing unsaturated FAs, such as omega-3 FAs, which showed generally beneficial effects on metabolic factors and liver fat content, although substantial heterogeneity persists among trials [51, 52]. In a recent Australian study in 50 overweight males, supplements containing omega-3 PUFAs from fish oil failed to show a benefit on liver fat content over 12 weeks [53]. With a high dose of $4 \mathrm{~g}$ /day for 8 weeks, a decrease of intrahepatic triglycerides by $19 \%$ was noted with a supplement containing omega-3 FA (eicosapentaenoic acid and docosahexaenoic acid) [54]. One year supplementation with $3 \mathrm{~g} /$ day of fish oil, however, did not improve histological activity in MASH patients [55]. Results from an Italian RCT suggest that an isocaloric diet, encompassing increased intake of MUFAs (from extra virgin olive oil), omega-3 (from salmon), and omega-6 PUFAs (from almonds) as well as fiber and vitamins D, E, and $\mathrm{C}$, might be more efficient in reducing liver fat than an isolated MUFA diet [19]. This concept of synergistic combination of nutrients is the basis of recommended diets such as the Mediterranean diet (MD).

\section{Carbohydrate Content}

CHOs, especially the low CHO diet (LCD; $<50 \%$ of the total energy intake from $\mathrm{CHO}$ ), have been investigated in the context of MAFLD. A meta-analysis of LCD showed no reduction of liver enzymes, but a mean reduction of intrahepatic lipid content by $11.5 \%$ in 4 studies, although significant heterogeneity was encountered [56]. Furthermore, the effect may have been confounded by weight loss across intervention groups. In 28 diabetic patients undergoing an isocaloric high-protein LCD, a hepatic fat content reduction by $2.4 \%$ compared to $0.2 \%$ under conventional diabetes diet was found without significant weight loss [57]. Mardinoglu et al. (2018) performed a multi-omics approach to characterize the metabolic effects of $\mathrm{CHO}$ restriction on MAFLD and found an increase in hepatic FA oxidation as well as reduced de novo lipogenesis and hepatic steatosis after 2 weeks of isocaloric high-protein LCD [58].

A subgroup of LCD studies has evaluated the effect of a ketogenic diet, which induces a state of ketosis by significant restriction of $\mathrm{CHO}$ intake, on MAFLD. A short-term hypocaloric, ketogenic intervention in 10 overweight individuals over 6 days increased nonesterified FAs, the main substrate for intrahepatic triglycerides, but reduced intrahepatic steatosis by $31 \%$, while increasing insulin sensitivity and metabolizing FAs towards ketogenesis [59]. In 262 diabetic patients who followed for 1 year an intervention based on LCD to induce self-monitored ketosis, noninvasively suspected steatosis and fibrosis resolved in $23 \%$ and $17 \%$ of patients, respectively, while no changes occurred in the control group [60]. However, evidence on the effects of a ketogenic diet in humans is scarce, and no uniform definition of this diet exists. More studies are needed to prove the safety of this approach in the specific context of patients with liver disease - particularly in those with advanced liver fibrosis.

As for the impact of free sugars, a meta-analysis failed to prove a negative effect of fructose, which is often contained in sweetened beverages and juices, on intrahepatic fat content in an isocaloric diet [61]. Recently, an 8-week open-label RCT of adolescent boys with histologically proven MAFLD, however, showed a mean difference of $-6.2 \%$ in hepatic steatosis after limiting the intake of free sugars to $<3 \%$ of the daily caloric intake $[62 \bullet \bullet]$.

\section{Fiber Content}

A diet rich in fiber is associated with a $15-30 \%$ reduction in all-cause and cardiovascular mortality as well as a lower risk for diabetes type 2 [63]. Several observational studies have suggested a lower intake of fiber in MAFLD patients 
compared to controls, although the exact impact is difficult to assess as fiber intake is often part of broader dietary patterns $[64,65]$. Among 70 obese individuals who underwent 6 months of two hypocaloric dietary regimens with identical energy deficit (RESMENA and AHA diets), the groups did not differ with regard to the improvement of noninvasive markers of liver health, and no association with macronutrient composition was observed [66]. Higher insoluble fiber $(\geq 7.5$ $\mathrm{g} /$ day) and fiber from fruit consumption, however, were associated with improvements of noninvasive scores and liver enzymes, respectively, indicating additional beneficial effects of fiber consumption with energy restriction.

\section{Protein Content}

Several studies have examined the impact of high-protein diets, often in combination with a hypocaloric regimen and LCD, on hepatic health. In an Iranian study of 92 patients who underwent a hypocaloric high-protein $\operatorname{diet}(25 \%$ of energy intake) with or without the addition of antioxidant $\beta$ cryptoxanthin, the high-protein groups showed a greater reduction in liver enzymes, but weight loss may have mediated this effect [16]. Among 19 bariatric patients, a hypocaloric high-protein diet (30\% of energy intake) over 3 weeks prior to surgery led to a decrease of steatosis by $42.6 \%$ compared to no effect under identical energy but lower protein intake [67].

Besides the amount of dietary protein, the source of proteins remains an issue for debate. Red and processed meats might contribute to MAFLD and other metabolic conditions, due to the high content of SFAs, nitrites and nitrates, heme iron, and branched-chain amino acids (BCAAs) which excess may be deleterious $[68,69]$. It has therefore been hypothesized that a vegetarian diet may aid in reducing MAFLD and other dysmetabolic conditions [70]. In a German study, 37 diabetic MAFLD patients were placed on a 6-week isocaloric diet with high-protein intake either from animal or plant-based sources [71]. While both diets reduced intrahepatic fat by 36$48 \%$, no negative metabolic effects of the omnivorous diet were detected.

\section{Specific Diets}

The methods described earlier are often combined into broader and comprehensive dietary patterns such as the MD.

The concept of the MD arose from the so-called Seven Countries Study, where it was first noted that a certain dietary pattern was linked to a decrease in cardiovascular disease and mortality $[72,73]$. While the MD generally contains plantbased foods and legumes instead of red meat and saturated FAs, direct comparison of trials is often hampered by the lack of a uniform definition [74]. Two large studies comparing the $\mathrm{MD}$ with a low-fat, high $\mathrm{CHO}$ diet showed an improvement in hepatic steatosis and insulin sensitivity [25, 75]. A greater decrease in intrahepatic fat was seen under MD. Reduction in ectopic fat deposits (including hepatic fat) was associated with improved cardiometabolic risk independent of overall weight loss [24]. Currently, the MD is the only specific diet recommended by the European Association for the Study of the Liver (EASL) guidelines [76].

It is unclear whether the recommendations used in the general population can be applied also to PLWH, but given its potential to lower the risk of lipodystrophy, MD may be favorable in PLWH.

\section{Micronutrients, Supplements, and Specific Foods}

A large body of research has focused on certain dietary compounds in the treatment of MAFLD, sometimes in the form of dietary supplements, a detailed summary of which is beyond the scope of this review. Hepatoprotective effects have been shown for an array of different foods, including antioxidants such as vitamin $\mathrm{E}$, as well as vitamin D probiotics and synbiotics [77, 78]. Among more readily consumed specific foods, the protective effect of coffee on MAFLD has recently been confirmed by a meta-analysis of observational studies that showed a pooled risk ratio of 0.68 for fibrosis in MAFLD patients who consumed coffee regularly [79].

\section{Nutritional Interventions in Patients with Cirrhosis}

Malnutrition is a common complication of cirrhosis. The nutritional evaluation in cirrhosis is however challenging for a variety of reasons: BMI (as well as DEXA) are affected by fluid retention; common biomarkers such as albumin and prealbumin are altered in the presence of impaired hepatic synthetic function $[80 \bullet, 81 \bullet \cdot]$. The lack of a gold standard to measure nutritional status in cirrhosis makes the study of nutritional interventions in this population particularly difficult.

\section{Energy/Calorie Supplementation}

Food intake is overall decreased in patients with cirrhosis, while the metabolic demand is increased. Hence, the main priority in nutritional interventions has been to provide an adequate amount of calories to correct this imbalance. Estimations based on indirect calorimetry and prior studies have led to the current recommendations by the European Society for Clinical Nutrition and Metabolism (ESPEN) and the EASL, i.e., a daily caloric intake of $30-35 \mathrm{kcal} / \mathrm{kg}$ of dry weight $\left[80 \bullet, 81 \bullet \cdot\right.$. In obese patients $\left(\mathrm{BMI}>30 \mathrm{~kg} / \mathrm{m}^{2}\right)$ with cirrhosis, a hypocaloric diet (-500-800 kcal/day) is recommended to achieve weight loss and fat mass reduction $[81 \bullet \bullet]$. 


\section{Macronutrient Composition}

\section{Protein Content}

The overall decreased food intake observed in cirrhosis is almost invariably associated with an inadequate protein intake. The current guidelines recommend a daily intake of $1.2-1.5 \mathrm{~g} / \mathrm{kg}$ of dry weight in nonobese individuals and $>1.5 \mathrm{~g} / \mathrm{kg}$ of ideal body weight in obese individuals with cirrhosis [81••]. The previous fear of inducing hepatic encephalopathy (HE) with highprotein diets (through hyperammonemia from protein deamination) is no longer a subject of debate, and protein restriction should not be prescribed, as it may worsen sarcopenia, which may in itself increase the risk of HE. Vegetable sources of protein could have additional benefits on HE given their lower content in aromatic amino acids and their higher fiber content compared to animal protein [81••]. A recent epidemiological cohort study comparing Turkish and American patients with cirrhosis suggested that coffee/tea, vegetable, and cereal consumption were associated with a higher intestinal microbial diversity and a lower 90-day hospitalization rate [82].

\section{BCAA Supplementation}

BCAAs (leucine, isoleucine, and valine) are essential amino acids involved in the metabolism of proteins, glucose, and fat [83]. Their plasma levels are often low in patients with cirrhosis, especially in the presence of sarcopenia, hyperammonemia, and HE. Two, earlier, well-designed studies (either using isocaloric/isoproteic supplements as control interventions or documenting similar calorie and protein intake in the BCAA and control groups) have demonstrated that BCAA supplementation could prevent the progression of liver failure and liverrelated events in patients with cirrhosis $[84,85]$. Since then, numerous studies (coming predominantly from Japan; the most recent are summarized in Table 2) have demonstrated a beneficial effect on muscle strength, ascites, edema, and HE (Fig. 1b) $[95 \cdot, 96]$. Additionally, two recent meta-analyses concluded that BCAAs [97] or BCAA-based late evening snacks (LES) [98] could help maintaining liver function after interventions for hepatocellular carcinoma (HCC), preventing ascites, edema, and HE. The beneficial effects of BCAAs may however be overestimated in some studies since part of it could be attributed to an overall increased calorie and protein intake in the BCAA group compared to the control group. Additionally, it is unclear if the severity of the liver disease has an impact on the response to BCAA supplementation $[89,99]$.

Both the ESPEN and the EASL recommend in their latest guidelines long-term oral BCAA supplementation when adequate intake is not achieved by oral diet (which is almost invariably the case in our personal experience) $[80 \bullet, 81 \bullet \bullet$. However, the optimal duration, dose, and amino acid ratio of BCAA supplementation remain unclear. For instance, the dose used in studies ranges between 5.5-30 g/day and 0.104-0.29 g/kg/day (Table 2) [95•]. A recent retrospective Korean study compared multiple doses and concluded that only the highest $(12.45 \mathrm{~g} /$ day, close to the ESPEN recommendation of $0.25 \mathrm{~g} / \mathrm{kg} / \mathrm{day}\left[80^{\bullet \bullet}\right]$ ) was effective [100], while other studies have observed benefits with doses as low as $6 \mathrm{~g} /$ day $[86,88]$. Regarding the composition of BCAA supplements, the amino acid ratio varies slightly in studies but approximates 2:1:1 of leucine, isoleucine, and valine, respectively (Table 2) [95•]. The use of leucine or its metabolite beta-hydroxy-beta-methyl-butyrate (HMB) is currently being evaluated in prospective studies.

Beyond their effects on the muscle, BCAAs may have other properties including a potential benefit on carcinogenesis, possibly through an enhanced immune function and improved hyperinsulinemia (reducing IGF-1- and VEGFmediated cell proliferation) [83]. Some studies have suggested that BCAAs could prevent HCC recurrence after treatment, although a recent meta-analysis concluded a nonstatistically significant effect [97]. More recently, an RCT in patients treated with radiofrequency ablation observed that oral supplementation with a BCAA-enriched supplement was associated with a decrease in HCC recurrence, better event-free survival, and better quality of life over a median follow-up period of 3.9 years (with similar total calorie and protein intake in both groups) [92•]. The effects of BCAAs on insulin resistance in cirrhosis remain unclear. A detailed description of the various potential targets and mechanisms of action of BCAAs is outside the scope of this review and can be found elsewhere [83].

\section{Other Macronutrients Composition and Specific Diets}

Although it is recommended in MAFLD, no prospective studies have looked at the impact of the MD in cirrhosis of any etiology, and the optimal proportion of fat and CHOs in the diet is unknown. In patients with ascites, the daily sodium intake should be moderate $(\sim 80 \mathrm{mmol}$, corresponding to $5 \mathrm{~g}$ of added salt) to keep the diet palatable $[81 \bullet \bullet]$.

\section{Efficacy of Energy/Calorie and Protein Supplementation}

Several studies have shown benefits of calorie and protein supplementation in patients with cirrhosis on various nutrition-related outcomes, mostly reflecting muscle mass (mid-arm muscle circumference, triceps skinfold thickness, CT-derived skeletal muscle index, DEXA, BIA with phase angle) and function (handgrip strength, cardiopulmonary endurance through 6-min walk test [6MWT], short physical performance battery, and Liver Frailty Index) [80••]. Other studies have observed benefits on clinical outcomes including infections, ascites, HE, complications after hepatectomy and liver transplantation, and some even on mortality (Fig. 1b), while others could not reach similar conclusions [101-103]. 


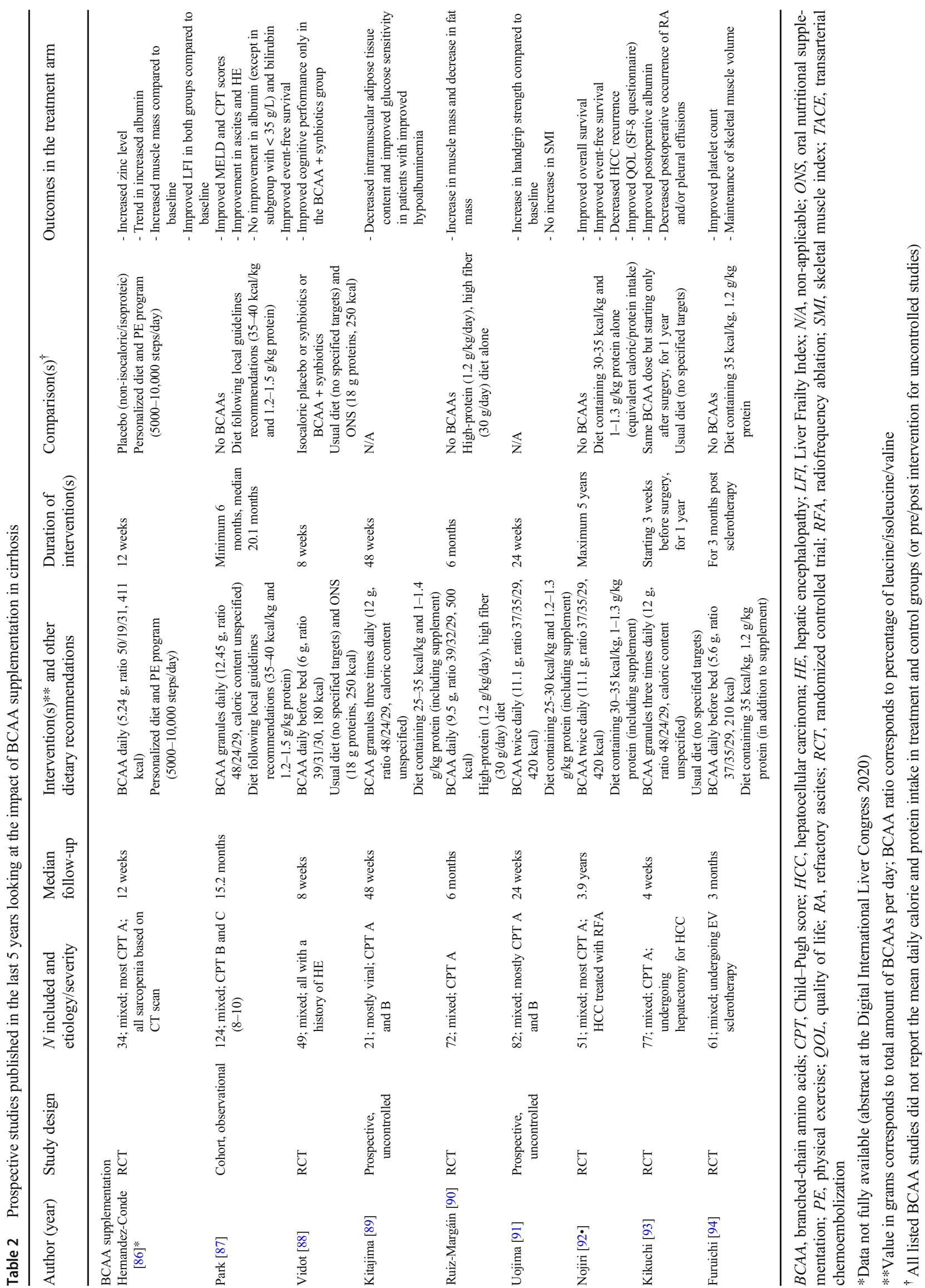


The discrepancy of findings and the inability of meta-analyses to draw firm conclusions on the prevention of complications in cirrhosis with DI can be explained by the significant study heterogeneity in design, included populations, type and duration of the intervention, presence and characteristics of the control group (including total daily calorie and protein intake in comparison to the treatment group, which is inconsistently reported), and follow-up. Nutritional supplementation may not be able to reverse some of the pathophysiological mechanisms of malnutrition (i.e., malabsorption, anabolic resistance) and could be futile in some specific situations, but reliable tools to predict who will or will not respond to nutritional therapy are not currently available. Therefore, it is reasonable to attempt DI in all patients with cirrhosis and malnutrition. Moreover, the intervention should last at least 3-6 months before concluding to any effect. Importantly, the involvement of a dietician in the management of cirrhosis was associated with better survival in a retrospective study [104].

\section{Special Considerations in Cirrhosis}

\section{Timing of Supplementation}

Since cirrhosis is a state of accelerated starvation (reached in only $10 \mathrm{~h}$ vs. 2-3 days in healthy individuals [105]), the timing of oral intake is of utmost importance. Fasting periods should be limited by the use of small and frequent meals of an LES and a breakfast. An earlier RCT showed that LES over a 12-month period improved total body protein, while the same supplement taken during daytime did not and was associated with a trend towards more complications, death, and transplantation [106]. The optimal caloric content of the LES has not been clearly defined, although some authors suggest a high caloric content (200-300 kcal) with a sufficient amount of CHOs (50 g) [107] and a source of protein, including BCAAs.

\section{Route of Supplementation}

The patient's oral intake must be evaluated regularly to ensure that the aforementioned targets are reached, otherwise oral nutritional supplementation should be implemented. The latter may however be difficult to tolerate for some patients, especially those with more advanced cirrhosis and dysgeusia, anorexia, or nausea. In this case, enteral nutrition (EN) should be strongly considered, at least temporarily. As for parenteral nutrition, experts agree that it should be reserved for patients with moderate to severe malnutrition who cannot adequately be fed by the oral and/or enteral route or who have contraindications to EN.

The feasibility of EN in the outpatient setting has recently been demonstrated in a retrospective case series looking at 14 patients with refractory ascites who failed to improve with oral nutritional support over a prior mean of 5 months (reasons not specified but likely due to intolerance) [108]. An outpatientbased, continuous, and supplementary EN (with a standard, fiber-enriched polymeric feed) for a median of 7 weeks, in addition to oral intake, was associated with significant benefits: an improvement in the nutritional status and handgrip strength, a significant improvement in ascites control with a decreased need for paracentesis, and a trend towards an improvement in the MELD score. Although all patients required reinsertion of the feeding tube at least once due to dislodgement or blockage, EN was overall well tolerated.

\section{Combining Nutritional Interventions with Physical Exercise}

While in MAFLD, PE mainly exerts its positive effects through weight loss, in cirrhosis, however, this effect seems to occur through maintaining/increasing muscle mass. The beneficial effects of PE on aerobic capacity, sarcopenia, and quality of life have repeatedly been shown in this population [109]. However, most of the studies evaluating the effects of exercise in cirrhosis incorporated a DI, and the observed effects could be due to diet alone or to a synergistic effect of diet and PE on muscle mass. Moreover, not all studies systematically report the patients' actual mean calorie and protein intake $[110,111]$. Studies looking at the effect of PE alone in cirrhosis are rare, and the isolated effect of physical exercise has not been well defined.

In a recent RCT in 39 patients with Child-Pugh A and B cirrhosis showing a beneficial effect of a 12-week resistance training program on muscle strength and size, both arms received nutritional counseling by a dietician, regular phone calls, and oral supplementation when the daily protein intake was under $1.2 \mathrm{~g} / \mathrm{kg}$ [112•]. Although the total protein intake was insufficient at the beginning of the study in both groups, it reached the target amount at the second dietician visit, showing the efficacy of the intervention. This was also observed in an earlier Canadian pilot RCT [113]. A study from the UK showing the feasibility of a hospital-based training program offered structured nutritional advice in both arms based on the EASL recommendations [114]. Two studies have also demonstrated a beneficial effect of a combined nutritional and PE intervention on portal pressure [115•, 116].

Since the benefits of PE depend on adequate substrate reserves, some authors have suggested optimizing the nutritional status of patients prior to starting an exercise program [117]. To compensate for the exercise-induced calorie expenditure, the consumption of an additional 250-300 kcal on exercise days [113] or a $20 \%$ increase in the caloric intake when following an exercise program [116] has been recommended.

Several recent studies have looked at the potential synergistic effect of PE (especially resistance training exercises) and BCAA supplementation. A pilot RCT showed that 
combining BCAA supplementation with a home-based PE program improved 6-min walk test (6MWT) distance and psoas muscle index more than BCAA supplementation alone (both groups also had a daily protein target intake of 1.2-1.5 $\mathrm{g} / \mathrm{kg}$ ) [118]. An uncontrolled study showed that BCAA supplementation and walking (2000 steps/day) increased muscle mass and function compared to baseline [119], while another small uncontrolled trial showed that BCAA supplementation and a home-based exercise program for 12 months improved aerobic capacity and glycemic control [120].

Regarding patients with cirrhosis and obesity, we previously showed that a 16-week intensive lifestyle intervention consisting of a personalized, hypocaloric, normoproteic diet, and $60 \mathrm{~min} /$ week of supervised PE led to an improvement in body weight and portal pressure in patients with compensated cirrhosis [115•]. Although the study used a combined intervention, it is likely that the hypocaloric diet was a major contributor to the observed weight loss. More studies are needed in this field, given the obesity pandemic and the high prevalence of sarcopenia in this population [121].

\section{Conclusions}

As highlighted in this review, dietary interventions have been proven effective in treating MAFLD/MASH in several large and well-conducted studies. The mainstay in overweight/ obese patients remains a daily (continuous or in an intermittent fashion) energy deficit of 500-1000 kcal, with a gradual reduction of 7-10\% of body weight, while lean patients might benefit from a reduction by 3-5\%. Dietary adjustments should include increased intake of unprocessed foods including fruits and vegetables, whole grains, fiber, and unsaturated FAs, for example, through the MD. Refined CHOs, SFAs, and red and processed meats should be limited.

On the other hand, the amount and quality of data regarding dietary interventions aimed at treating and reverting malnutrition in cirrhosis are more limited. Meta-analyses could not prove the efficacy of DI in cirrhosis, probably in part due to the heterogeneity of studies in this field. DI including BCAAs supplementation (especially as a late snack) in addition to calorie and protein supplementation have demonstrated the potential of improving clinical outcomes in this setting.

There are many challenges to the applicability of these interventions in both MAFLD and cirrhosis populations. Adherence from the healthcare providers to nutritional recommendations remains suboptimal, and guidelines need to include pragmatic and feasible recommendations to improve adherence. In addition, and maybe most importantly, healthcare providers and patients need to be educated on malnutrition and its impact on the evolution of chronic liver diseases [122]. As for patients' awareness and empowerment, simple educational interventions, such as a simple nutrition education class followed by reinforcement phone calls, have been shown to be beneficial [78, 123-125].

The success of DI also strongly depends on proper screening and identification of patients who might benefit from them and from the availability of a structured and well-connected multidisciplinary team. This must include, in addition to the hepatologist and an exercise specialist, a registered nutritionist, who can properly evaluate the patient's nutritional status and provide tailored recommendations (taking also into account the patient's preferences and socioeconomic factors), as well as retroaction and strategy modifications if objectives are not met. The support of a psychologist might be required to improve adherence, particularly in patients with obesity and in patients with anxiety and depression (frequently observed in obese patients with MAFLD and in patients with cirrhosis).

Barriers to the implementation of nutritional interventions need to be identified early and optimized, since these are frequent, particularly in patients with cirrhosis [126]. Finally, further studies should focus on how new technologies can be applied in this field, for instance, to increase adherence to DI (e.g., reinforcement strategies via reminders) or to make expert knowledge more universally available (e.g., web-based programs). Well-designed randomized controlled studies adding targeted DI to standard of care vs. standard of care alone with robust endpoints (e.g., decrease of complications or mortality) in patients with cirrhosis and in particular decompensated cirrhosis are a major unmet need in hepatology.

Acknowledgements EVL is recipient of the Canadian Association for the Study of the Liver CASL-CLF Clinical Hepatology Fellowship. NL is supported by the Stiftung für Leberkrankheiten, Bern. CR is recipient of the Protected Research Time Grant for PhD students of the University of Bern.

Funding Open Access funding provided by Universität Bern.

\section{Declarations}

Conflict of Interest The authors have no potential conflicts (financial, professional, or personal) that are relevant to the manuscript to disclose.

Human and Animal Rights and Informed Consent This article does not contain any studies with human or animal subjects performed by any of the authors.

Open Access This article is licensed under a Creative Commons Attribution 4.0 International License, which permits use, sharing, adaptation, distribution and reproduction in any medium or format, as long as you give appropriate credit to the original author(s) and the source, provide a link to the Creative Commons licence, and indicate if changes were made. The images or other third party material in this article are included in the article's Creative Commons licence, unless indicated otherwise in a credit line to the material. If material is not included in the article's Creative Commons licence and your intended use is not permitted by statutory regulation or exceeds the permitted use, you will need to obtain permission directly from the copyright holder. To view a copy of this licence, visit http://creativecommons.org/licenses/by/4.0/. 


\section{References}

Papers of particular interest, published recently, have been highlighted as:

- Of importance

•- Of major importance

1. Di Ciaula A, Baj J, Garruti G, Celano G, De Angelis M, Wang $\mathrm{HH}$, et al. Liver steatosis, gut-liver axis, microbiome and environmental factors. A never-ending bidirectional cross-talk. J Clin Med. 2020;9(8).

2. Geier A, Tiniakos D, Denk H, Trauner M. From the origin of NASH to the future of metabolic fatty liver disease. Gut. 2021. Recent review on NASH and MAFLD.

3. Morse CG, McLaughlin M, Matthews L, Proschan M, Thomas F, Gharib AM, et al. Nonalcoholic steatohepatitis and hepatic fibrosis in HIV-1-monoinfected adults with elevated aminotransferase levels on antiretroviral therapy. Clin Infect Dis. 2015;60(10): 1569-78.

4. Pembroke T, Deschenes M, Lebouche B, Benmassaoud A, Sewitch M, Ghali P, et al. Hepatic steatosis progresses faster in HIV mono-infected than HIV/HCV co-infected patients and is associated with liver fibrosis. J Hepatol. 2017;67(4):801-8.

5. Vodkin I, Valasek MA, Bettencourt R, Cachay E, Loomba R. Clinical, biochemical and histological differences between HIVassociated NAFLD and primary NAFLD: a case-control study. Aliment Pharmacol Ther. 2015;41(4):368-78.

6. Nunez M. Clinical syndromes and consequences of antiretroviralrelated hepatotoxicity. Hepatology (Baltimore, Md). 2010;52(3): $1143-55$.

7. Guaraldi G, Lonardo A, Maia L, Palella FJ, Jr. Metabolic concerns in aging HIV-infected persons: from serum lipid phenotype to fatty liver. AIDS (London, England). 2017;31 Suppl 2:S147Ss56.

8. Sax PE, Erlandson KM, Lake JE, McComsey GA, Orkin C, Esser $\mathrm{S}$, et al. Weight gain following initiation of antiretroviral therapy: risk factors in randomized comparative clinical trials. Clin Infect Dis. 2020;71(6):1379-89.

9. Venter WDF, Moorhouse M, Sokhela S, Fairlie L, Mashabane N, Masenya M, et al. Dolutegravir plus two different prodrugs of tenofovir to treat HIV. N Engl J Med. 2019;381(9):803-15.

10. Bourgi K, Jenkins CA, Rebeiro PF, Palella F, Moore RD, Altoff $\mathrm{KN}$, et al. Weight gain among treatment-naive persons with HIV starting integrase inhibitors compared to non-nucleoside reverse transcriptase inhibitors or protease inhibitors in a large observational cohort in the United States and Canada. J Int AIDS Soc. 2020;23(4):e25484.

11. Bakal DR, Coelho LE, Luz PM, Clark JL, De Boni RB, Cardoso $\mathrm{SW}$, et al. Obesity following ART initiation is common and influenced by both traditional and HIV-/ART-specific risk factors. J Antimicrob Chemother. 2018;73(8):2177-85.

12. Hsu R, Brunet L, Fusco JS, Mounzer K, Vannappagari V, Henegar C, et al. 341. Risk of type 2 diabetes mellitus after antiretroviral therapy initiation in individuals living with HIV in the United States: open forum infect dis. 2019;6(Suppl 2):S181-2. https://doi.org/10.1093/ofid/ofz360.414. eCollection 2019 Oct.

13. Leoni S, Tovoli F, Napoli L, Serio I, Ferri S, Bolondi L. Current guidelines for the management of non-alcoholic fatty liver disease: a systematic review with comparative analysis. World $\mathrm{J}$ Gastroenterol. 2018;24(30):3361-73.

14. EACS. European AIDS Clinical Society Guidelines 2020.

15. WHO. Diet, nutrition and the prevention of chronic diseases. 2003

16. Haidari F, Hojhabrimanesh A, Helli B, Seyedian S-S, AhmadiAngali K, Abiri B. A hypocaloric high-protein diet supplemented with $\beta$-cryptoxanthin improves non-alcoholic fatty liver disease: a randomized controlled trial. BMC Gastroenterol. 2020;20(1):349.

17. Nourian M, Askari G, Golshiri P, Miraghajani M, Shokri S, Arab A. Effect of lifestyle modification education based on health belief model in overweight/obese patients with non-alcoholic fatty liver disease: a parallel randomized controlled clinical trial. Clin Nutr ESPEN. 2020;38:236-41.

18. Campanella A, Iacovazzi PA, Misciagna G, Bonfiglio C, Mirizzi A, Franco I, et al. The effect of three Mediterranean diets on remnant cholesterol and non-alcoholic fatty liver disease: a secondary analysis. Nutrients. 2020;12(6).

19. Della Pepa G, Vetrani C, Brancato V, Vitale M, Monti S, Annuzzi $\mathrm{G}$, et al. Effects of a multifactorial ecosustainable isocaloric diet on liver fat in patients with type 2 diabetes: randomized clinical trial. BMJ Open Diabetes Res Care. 2020;8(1).

20. Cai H, Qin Y-L, Shi Z-Y, Chen J-H, Zeng M-J, Zhou W, et al. Effects of alternate-day fasting on body weight and dyslipidaemia in patients with non-alcoholic fatty liver disease: a randomised controlled trial. BMC Gastroenterol. 2019;19(1):219.

21. Marin-Alejandre BA, Abete I, Cantero I, Monreal JI, Elorz M, Herrero JI, et al. The metabolic and hepatic impact of two personalized dietary strategies in subjects with obesity and nonalcoholic fatty liver disease: the fatty liver in obesity $(\mathrm{FLiO})$ randomized controlled trial. Nutrients. 2019;11(10).

22. Rosqvist F, Kullberg J, Ståhlman M, Cedernaes J, Heurling K, Johansson $\mathrm{H}-\mathrm{E}$, et al. Overeating saturated fat promotes fatty liver and ceramides compared with polyunsaturated fat: a randomized trial. J Clin Endocrinol Metab. 2019;104(12):6207-19.

23. Arab A, Hadi A, Moosavian SP, Rafie N, Hajianfar H. The effect of nutrition education program on overweight/obese patients with non-alcoholic fatty liver disease: a single-blind parallel randomized controlled trial. Clin Nutr Res. 2019;8(3):238-46.

24. Gepner Y, Shelef I, Komy O, Cohen N, Schwarzfuchs D, Bril N, et al. The beneficial effects of Mediterranean diet over low-fat diet may be mediated by decreasing hepatic fat content. J Hepatol. 2019;71(2):379-88.

25. Gepner Y, Shelef I, Schwarzfuchs D, Zelicha H, Tene L, Yaskolka Meir A, et al. Effect of distinct lifestyle interventions on mobilization of fat storage pools: CENTRAL magnetic resonance imaging randomized controlled trial. Circulation. 2018;137(11):1143-57.

26. Shojasaadat F, Ayremlou P, Hashemi A, Mehdizadeh A, Zarrin R. A randomized controlled trial comparing effects of a low-energy diet with $\mathrm{n}-3$ polyunsaturated fatty acid supplementation in patients with non-alcoholic fatty liver disease. J Res Med Sci. 2019;24.

27. Willmann C, Heni M, Linder K, Wagner R, Stefan N, Machann J, et al. Potential effects of reduced red meat compared with increased fiber intake on glucose metabolism and liver fat content: a randomized and controlled dietary intervention study. Am J Clin Nutr. 2019;109(2):288-96.

28. Jang EC, Jun DW, Lee SM, Cho YK, Ahn SB. Comparison of efficacy of low-carbohydrate and low-fat diet education programs in non-alcoholic fatty liver disease: a randomized controlled study. Hepatol Res. 2018;48(3):E22-E9.

29. Wong VW-S, Wong GL-H, Chan RS-M, Shu SS-T, Cheung BH$\mathrm{K}$, Li LS, et al. Beneficial effects of lifestyle intervention in nonobese patients with non-alcoholic fatty liver disease. J Hepatol. 2018;69(6):1349-56 RCT demonstrating beneficial effects of modest weight loss also for lean individuals with MAFLD.

30. Properzi C, O'Sullivan TA, Sherriff JL, Ching HL, Jeffrey GP, Buckley RF, et al. Ad libitum Mediterranean and low-fat diets both significantly reduce hepatic steatosis: a randomized controlled trial. Hepatology. 2018;68(5):1741-54.

31. Chan DFY, So HK, Hui SCN, Chan RSM, Li AM, Sea MM, et al. Dietitian-led lifestyle modification programme for obese Chinese adolescents with non-alcoholic fatty liver disease: a randomized controlled study. Int J Obes. 2018;42(9):1680-90. 
32. Katsagoni CN, Papatheodoridis GV, Ioannidou P, Deutsch M, Alexopoulou A, Papadopoulos N, et al. Improvements in clinical characteristics of patients with non-alcoholic fatty liver disease, after an intervention based on the Mediterranean lifestyle: a randomised controlled clinical trial. Br J Nutr. 2018;120(2):164-75.

33. Holmer ML, C.; Petersson, S.; Moshtaghi-Svensson, J.; Tillander, V.; Brismar, TB.; Hagström, H.; Stål, P. Treatment of NAFLD with intermittent calorie restriction or lowcarb high-fat diet - a randomized controlled trial. JHEP reports: innovation in hepatology. 2021:100256.

34. Dixon JB, Bhathal PS, Hughes NR, O'Brien PE. Nonalcoholic fatty liver disease: improvement in liver histological analysis with weight loss. Hepatology. 2004;39(6):1647-54.

35. Koutoukidis DA, Astbury NM, Tudor KE, Morris E, Henry JA, Noreik M, et al. Association of weight loss interventions with changes in biomarkers of nonalcoholic fatty liver disease: a systematic review and meta-analysis. JAMA Intern Med. 2019;179(9):1262-71 Meta-analysis showing association between weight loss interventions and improved liver biomarkers in MAFLD.

36. Ueno T, Sugawara H, Sujaku K, Hashimoto O, Tsuji R, Tamaki S, et al. Therapeutic effects of restricted diet and exercise in obese patients with fatty liver. J Hepatol. 1997;27(1):103-7.

37. Harrison SA, Fecht W, Brunt EM, Neuschwander-Tetri BA. Orlistat for overweight subjects with nonalcoholic steatohepatitis: a randomized, prospective trial. Hepatology. 2009;49(1):80-6.

38. Malespin MH, Barritt AS, Watkins SE, Schoen C, Tincopa MA, Corbin KD, et al. Weight loss and weight regain in usual clinical practice: results from the TARGET-NASH observational cohort. Clin Gastroenterol Hepatol. 2021.

39. Hernandez Roman J, Patel S. Why do lifestyle recommendations fail in most patients with nonalcoholic fatty liver disease? Gastroenterol Clin N Am. 2020;49(1):95-104.

40. Lazo M, Solga SF, Horska A, Bonekamp S, Diehl AM, Brancati FL, et al. Effect of a 12-month intensive lifestyle intervention on hepatic steatosis in adults with type 2 diabetes. Diabetes Care. 2010;33(10):2156-63.

41. Promrat K, Kleiner DE, Niemeier HM, Jackvony E, Kearns M, Wands JR, et al. Randomized controlled trial testing the effects of weight loss on nonalcoholic steatohepatitis (NASH). Hepatology. 2010;51(1):121-9.

42. Vilar-Gomez E, Martinez-Perez Y, Calzadilla-Bertot L, TorresGonzalez A, Gra-Oramas B, Gonzalez-Fabian L, et al. Weight loss through lifestyle modification significantly reduces features of nonalcoholic steatohepatitis. Gastroenterology. 2015;149(2):367-78.e5.

43. Hamurcu Varol P, Kaya E, Alphan E, Yilmaz Y. Role of intensive dietary and lifestyle interventions in the treatment of lean nonalcoholic fatty liver disease patients. Eur J Gastroenterol Hepatol. 2020;32(10):1352-7.

44. Koopman KE, Caan MWA, Nederveen AJ, Pels A, Ackermans MT, Fliers E, et al. Hypercaloric diets with increased meal frequency, but not meal size, increase intrahepatic triglycerides: a randomized controlled trial. Hepatology. 2014;60(2):545-53.

45. Rynders CA, Thomas EA, Zaman A, Pan Z, Catenacci VA, Melanson EL. Effectiveness of intermittent fasting and timerestricted feeding compared to continuous energy restriction for weight loss. Nutrients. 2019;11(10).

46. Johari MI, Yusoff K, Haron J, Nadarajan C, Ibrahim KN, Wong MS, et al. A randomised controlled trial on the effectiveness and adherence of modified alternate-day calorie restriction in improving activity of non-alcoholic fatty liver disease. Sci Rep. 2019;9(1):11232.

47. Toshimitsu K, Matsuura B, Ohkubo I, Niiya T, Furukawa S, Hiasa $\mathrm{Y}$, et al. Dietary habits and nutrient intake in non-alcoholic steatohepatitis. Nutrition. 2007;23(1):46-52.
48. Luukkonen PK, Sädevirta S, Zhou Y, Kayser B, Ali A, Ahonen L, et al. Saturated fat is more metabolically harmful for the human liver than unsaturated fat or simple sugars. Diabetes Care. 2018;41(8):1732-9.

49. Rosqvist F, Iggman D, Kullberg J, Cedernaes J, Johansson H-E, Larsson A, et al. Overfeeding polyunsaturated and saturated fat causes distinct effects on liver and visceral fat accumulation in humans. Diabetes. 2014;63(7):2356-68.

50. Errazuriz I, Dube S, Slama M, Visentin R, Nayar S, O’Connor H, et al. Randomized controlled trial of a MUFA or fiber-rich diet on hepatic fat in prediabetes. J Clin Endocrinol Metab. 2017;102(5): 1765-74.

51. Lu W, Li S, Li J, Wang J, Zhang R, Zhou Y, et al. Effects of omega-3 fatty acid in nonalcoholic fatty liver disease: a metaanalysis. Gastroenterol Res Pract. 2016;2016:1459790.

52. Musa-Veloso K, Venditti C, Lee HY, Darch M, Floyd S, West S, et al. Systematic review and meta-analysis of controlled intervention studies on the effectiveness of long-chain omega-3 fatty acids in patients with nonalcoholic fatty liver disease. Nutr Rev. 2018;76(8):581-602.

53. Parker HM, Cohn JS, O'Connor HT, Garg ML, Caterson ID, George J, et al. Effect of fish oil supplementation on hepatic and visceral fat in overweight men: a randomized controlled trial. Nutrients. 2019;11(2).

54. Green CJ, Pramfalk C, Charlton CA, Gunn PJ, Cornfield T, Pavlides M, et al. Hepatic de novo lipogenesis is suppressed and fat oxidation is increased by omega-3 fatty acids at the expense of glucose metabolism. BMJ Open Diabetes Res Care. 2020;8(1).

55. Argo CK, Patrie JT, Lackner C, Henry TD, de Lange EE, Weltman AL, et al. Effects of n-3 fish oil on metabolic and histological parameters in NASH: a double-blind, randomized, placebo-controlled trial. J Hepatol. 2015;62(1):190-7.

56. Haghighatdoost F, Salehi-Abargouei A, Surkan PJ, Azadbakht L. The effects of low carbohydrate diets on liver function tests in nonalcoholic fatty liver disease: a systematic review and metaanalysis of clinical trials. J Res Med Sci. 2016;21:53.

57. Skytte MJ, Samkani A, Petersen AD, Thomsen MN, Astrup A, Chabanova E, et al. A carbohydrate-reduced high-protein diet improves $\mathrm{HbA} 1 \mathrm{c}$ and liver fat content in weight stable participants with type 2 diabetes: a randomised controlled trial. Diabetologia. 2019;62(11):2066-78.

58. Mardinoglu A, Wu H, Bjornson E, Zhang C, Hakkarainen A, Räsänen SM, et al. An integrated understanding of the rapid metabolic benefits of a carbohydrate-restricted diet on hepatic steatosis in humans. Cell Metab. 2018;27(3):559-71.e5.

59. Luukkonen PK, Dufour S, Lyu K, Zhang X-M, Hakkarainen A, Lehtimäki TE, et al. Effect of a ketogenic diet on hepatic steatosis and hepatic mitochondrial metabolism in nonalcoholic fatty liver disease. Proc Natl Acad Sci U S A. 2020;117(13):7347-54.

60. Vilar-Gomez E, Athinarayanan SJ, Adams RN, Hallberg SJ, Bhanpuri NH, McKenzie AL, et al. Post hoc analyses of surrogate markers of non-alcoholic fatty liver disease (NAFLD) and liver fibrosis in patients with type 2 diabetes in a digitally supported continuous care intervention: an open-label, non-randomised controlled study. BMJ Open. 2019;9(2):e023597.

61. Chiu S, Sievenpiper JL, de Souza RJ, Cozma AI, Mirrahimi A, Carleton AJ, et al. Effect of fructose on markers of non-alcoholic fatty liver disease (NAFLD): a systematic review and metaanalysis of controlled feeding trials. Eur J Clin Nutr. 2014;68(4): 416-23.

62.• Schwimmer JB, Ugalde-Nicalo P, Welsh JA, Angeles JE, Cordero $\mathrm{M}$, Harlow KE, et al. Effect of a low free sugar diet vs usual diet on nonalcoholic fatty liver disease in adolescent boys: a randomized clinical trial. JAMA. 2019;321(3):256-65 Controlled trial showing the benefit of a relatively simple intervention targeting intake of free sugar on steatosis among adolescent boys. 
63. Reynolds A, Mann J, Cummings J, Winter N, Mete E, Morenga LT. Carbohydrate quality and human health: a series of systematic reviews and meta-analyses. Lancet. 2019;393(10170):434-45.

64. Wehmeyer MH, Zyriax B-C, Jagemann B, Roth E, Windler E, Schulze Zur Wiesch J, et al. Nonalcoholic fatty liver disease is associated with excessive calorie intake rather than a distinctive dietary pattern. Medicine (Baltimore). 2016;95(23):e3887.

65. Zolfaghari H, Askari G, Siassi F, Feizi A, Sotoudeh G. Intake of nutrients, fiber, and sugar in patients with nonalcoholic fatty liver disease in comparison to healthy individuals. Int J Prev Med. 2016;7:98.

66. Cantero I, Abete I, Monreal JI, Martinez JA, Zulet MA. Fruit fiber consumption specifically improves liver health status in obese subjects under energy restriction. Nutrients. 2017;9(7):667.

67. Xu C, Markova M, Seebeck N, Loft A, Hornemann S, Gantert T, et al. High-protein diet more effectively reduces hepatic fat than low-protein diet despite lower autophagy and FGF21 levels. Liver Int. 2020.

68. Wolk A. Potential health hazards of eating red meat. J Intern Med. 2017;281(2):106-22.

69. Alferink LJ, Kiefte-de Jong JC, Erler NS, Veldt BJ, Schoufour JD, de Knegt RJ, et al. Association of dietary macronutrient composition and non-alcoholic fatty liver disease in an ageing population: the Rotterdam study. Gut. 2019;68(6):1088-98.

70. McCarty MF. GCN2 and FGF21 are likely mediators of the protection from cancer, autoimmunity, obesity, and diabetes afforded by vegan diets. Med Hypotheses. 2014;83(3):365-71.

71. Markova M, Pivovarova O, Hornemann S, Sucher S, Frahnow T, Wegner $\mathrm{K}$, et al. Isocaloric diets high in animal or plant protein reduce liver fat and inflammation in individuals with type 2 diabetes. Gastroenterology. 2017;152(3):571-85.e8.

72. Keys A, Menotti A, Karvonen MJ, Aravanis C, Blackburn H, Buzina R, et al. The diet and 15-year death rate in the Seven Countries Study. Am J Epidemiol. 1986;124(6):903-15.

73. Fidanza F, Alberti A, Lanti M, Menotti A. Mediterranean Adequacy Index: correlation with 25-year mortality from coronary heart disease in the Seven Countries Study. Nutr Metab Cardiovasc Dis. 2004;14(5):254-8.

74. Davis C, Bryan J, Hodgson J, Murphy K. Definition of the Mediterranean diet; a literature review. Nutrients. 2015;7(11): 9139-53.

75. Ryan MC, Itsiopoulos C, Thodis T, Ward G, Trost N, Hofferberth $\mathrm{S}$, et al. The Mediterranean diet improves hepatic steatosis and insulin sensitivity in individuals with non-alcoholic fatty liver disease. J Hepatol. 2013;59(1):138-43.

76. Easl-Easd-Easo. EASL-EASD-EASO Clinical practice guidelines for the management of non-alcoholic fatty liver disease. $\mathrm{J}$ Hepatol. 2016;64(6):1388-402.

77. Silva Figueiredo P, Inada AC, Ribeiro Fernandes M, Granja Arakaki D, Freitas KdC, Avellaneda Guimarães RdC, et al. An overview of novel dietary supplements and food ingredients in patients with metabolic syndrome and non-alcoholic fatty liver disease. Molecules (Basel, Switzerland). 2018;23(4).

78. Liu L, Li P, Liu Y, Zhang Y. Efficacy of probiotics and synbiotics in patients with nonalcoholic fatty liver disease: a meta-analysis. Dig Dis Sci. 2019;64(12):3402-12.

79. Hayat U, Siddiqui AA, Okut H, Afroz S, Tasleem S, Haris A. The effect of coffee consumption on the non-alcoholic fatty liver disease and liver fibrosis: a meta-analysis of 11 epidemiological studies. Ann Hepatol. 2020.

80.• Plauth M, Bernal W, Dasarathy S, Merli M, Plank LD, Schutz T, et al. ESPEN guideline on clinical nutrition in liver disease. Clin Nutr. 2019;38(2):485-521 ESPEN recommendations on nutrition in liver disease.

81.• European Association for the Study of the Liver. Electronic address EEE, European Association for the Study of the L. EASL
Clinical practice guidelines on nutrition in chronic liver disease. $\mathrm{J}$ Hepatol. 2019;70(1):172-93 EASL recommendations on nutrition in liver disease.

82. Bajaj JS, Idilman R, Mabudian L, Hood M, Fagan A, Turan D, et al. Diet affects gut microbiota and modulates hospitalization risk differentially in an international cirrhosis cohort. Hepatology. 2018;68(1):234-47.

83. Tajiri K, Shimizu Y. Branched-chain amino acids in liver diseases. Transl Gastroenterol Hepatol. 2018;3:47.

84. Marchesini G, Bianchi G, Merli M, Amodio P, Panella C, Loguercio C, et al. Nutritional supplementation with branchedchain amino acids in advanced cirrhosis: a double-blind, randomized trial. Gastroenterology. 2003;124(7):1792-801.

85. Muto Y, Sato S, Watanabe A, Moriwaki H, Suzuki K, Kato A, et al. Effects of oral branched-chain amino acid granules on eventfree survival in patients with liver cirrhosis. Clin Gastroenterol Hepatol. 2005;3(7):705-13.

86. Hernández Conde M, Llop E, Tormo B, Perelló C, López-Gómez M, Abad Guerra J, et al. Supplementation with branched-chain amino acids improves muscle mass of cirrhotic patients with sarcopenia. J Hepatol. 2020;73:S37-S8.

87. Park JG, Tak WY, Park SY, Kweon YO, Chung WJ, Jang BK, et al. Effects of branched-chain amino acid (BCAA) supplementation on the progression of advanced liver disease: a Korean nationwide, multicenter, prospective, observational, cohort study. Nutrients. 2020;12(5).

88. Vidot H, Cvejic E, Finegan LJ, Shores EA, Bowen DG, Strasser SI, et al. Supplementation with synbiotics and/or branched chain amino acids in hepatic encephalopathy: a pilot randomised placebo-controlled clinical study. Nutrients. 2019;11(8).

89. Kitajima Y, Takahashi H, Akiyama T, Murayama K, Iwane S, Kuwashiro T, et al. Supplementation with branched-chain amino acids ameliorates hypoalbuminemia, prevents sarcopenia, and reduces fat accumulation in the skeletal muscles of patients with liver cirrhosis. J Gastroenterol. 2018;53(3):427-37.

90. Ruiz-Margain A, Mendez-Guerrero O, Roman-Calleja BM, Gonzalez-Rodriguez S, Fernandez-Del-Rivero G, RodriguezCordova PA, et al. Dietary management and supplementation with branched-chain amino acids in cirrhosis of the liver. Rev Gastroenterol Mex. 2018;83(4):424-33.

91. Uojima H, Sakurai S, Hidaka H, Kinbara T, Sung JH, Ichita C, et al. Effect of branched-chain amino acid supplements on muscle strength and muscle mass in patients with liver cirrhosis. Eur $\mathrm{J}$ Gastroenterol Hepatol. 2017;29(12):1402-7.

92. Nojiri S, Fujiwara K, Shinkai N, Iio E, Joh T. Effects of branchedchain amino acid supplementation after radiofrequency ablation for hepatocellular carcinoma: a randomized trial. Nutrition. 2017;33:20-7 RCT with a long follow-up period showing an improved event-free survival with BCAA supplementation after RFA for HCC.

93. Kikuchi Y, Hiroshima Y, Matsuo K, Kawaguchi D, Murakami T, Yabushita $\mathrm{Y}$, et al. A randomized clinical trial of preoperative administration of branched-chain amino acids to prevent postoperative ascites in patients with liver resection for hepatocellular carcinoma. Ann Surg Oncol. 2016;23(11):3727-35.

94. Furuichi Y, Imai Y, Miyata Y, Sugimoto K, Sano T, Taira J, et al. Branched-chain amino acid-enriched nutrient increases blood platelet count in patients after endoscopic injection sclerotherapy. Hepatol Res. 2016;46(11):1129-36.

95. Ooi PH, Gilmour SM, Yap J, Mager DR. Effects of branched chain amino acid supplementation on patient care outcomes in adults and children with liver cirrhosis: a systematic review. Clin Nutr ESPEN. 2018;28:41-51 Important systematic review summarizing the effects of BCAA supplementation in cirrhosis. 
96. Gluud LL, Dam G, Les I, Marchesini G, Borre M, Aagaard NK, et al. Branched-chain amino acids for people with hepatic encephalopathy. Cochrane Database Syst Rev. 2017;5:CD001939.

97. Chen L, Chen Y, Wang X, Li H, Zhang H, Gong J, et al. Efficacy and safety of oral branched-chain amino acid supplementation in patients undergoing interventions for hepatocellular carcinoma: a meta-analysis. Nutr J. 2015;14:67.

98. Chen CJ, Wang LC, Kuo HT, Fang YC, Lee HF. Significant effects of late evening snack on liver functions in patients with liver cirrhosis: a meta-analysis of randomized controlled trials. J Gastroenterol Hepatol. 2019;34(7):1143-52.

99. Hanai T, Shiraki M, Imai K, Suetsugu A, Takai K, Shimizu M. Late evening snack with branched-chain amino acids supplementation improves survival in patients with cirrhosis. J Clin Med. 2020;9(4).

100. Park JG, Tak WY, Park SY, Kweon YO, Jang SY, Lee YR, et al. Effects of branched-chain amino acids (BCAAs) on the progression of advanced liver disease: a Korean nationwide, multicenter, retrospective, observational, cohort study. Medicine. 2017;96(24): e6580.

101. Koretz RL, Avenell A, Lipman TO. Nutritional support for liver disease. Cochrane Database Syst Rev. 2012;5:CD008344.

102. Ney M, Vandermeer B, van Zanten SJ, Ma MM, Gramlich L, Tandon P. Meta-analysis: oral or enteral nutritional supplementation in cirrhosis. Aliment Pharmacol Ther. 2013;37(7):672-9.

103. Fialla AD, Israelsen M, Hamberg O, Krag A, Gluud LL. Nutritional therapy in cirrhosis or alcoholic hepatitis: a systematic review and meta-analysis. Liver Int. 2015;35(9):2072-8.

104. Iwasa M, Iwata K, Hara N, Hattori A, Ishidome M, SekoguchiFujikawa N, et al. Nutrition therapy using a multidisciplinary team improves survival rates in patients with liver cirrhosis. Nutrition. 2013;29(11-12):1418-21.

105. Owen OE, Trapp VE, Reichard GA Jr, Mozzoli MA, Moctezuma $\mathrm{J}$, Paul P, et al. Nature and quantity of fuels consumed in patients with alcoholic cirrhosis. J Clin Invest. 1983;72(5):1821-32.

106. Plank LD, Gane EJ, Peng S, Muthu C, Mathur S, Gillanders L, et al. Nocturnal nutritional supplementation improves total body protein status of patients with liver cirrhosis: a randomized 12month trial. Hepatology. 2008;48(2):557-66.

107. Tsien CD, McCullough AJ, Dasarathy S. Late evening snack: exploiting a period of anabolic opportunity in cirrhosis. J Gastroenterol Hepatol. 2012;27(3):430-41.

108. Vidot H, Bowen DG, Carey S, McCaughan GW, Allman-Farinelli M, Shackel NA. Aggressive nutrition intervention reduces ascites and frequency of paracentesis in malnourished patients with cirrhosis and ascites. JGH Open. 2017;1(3):92-7.

109. Williams FR, Berzigotti A, Lord JM, Lai JC, Armstrong MJ. Review article: impact of exercise on physical frailty in patients with chronic liver disease. Aliment Pharmacol Ther. 2019;50(9): 988-1000.

110. Kruger C, McNeely ML, Bailey RJ, Yavari M, Abraldes JG, Carbonneau M, et al. Home exercise training improves exercise capacity in cirrhosis patients: role of exercise adherence. Sci Rep. 2018;8(1):99.

111. Wallen MP, Keating SE, Hall A, Hickman IJ, Pavey TG, Woodward AJ, et al. Exercise training is safe and feasible in patients awaiting liver transplantation: a pilot randomized controlled trial. Liver Transpl. 2019;25(10):1576-80.

112. Aamann L, Dam G, Borre M, Drljevic-Nielsen A, Overgaard K, Andersen $\mathrm{H}$, et al. Resistance training increases muscle strength and muscle size in patients with liver cirrhosis. Clin Gastroenterol Hepatol. 2020;18(5):1179-87 e6 RCT focusing on the effects of an exercise program but confirming the efficacy of regular nutritional advice to help reaching recommended protein intake targets.

113. Zenith L, Meena N, Ramadi A, Yavari M, Harvey A, Carbonneau $\mathrm{M}$, et al. Eight weeks of exercise training increases aerobic capacity and muscle mass and reduces fatigue in patients with cirrhosis. Clin Gastroenterol Hepatol. 2014;12(11):1920-6 e2.

114. Morkane CM, Kearney O, Bruce DA, Melikian CN, Martin DS. An outpatient hospital-based exercise training program for patients with cirrhotic liver disease awaiting transplantation: a feasibility trial. Transplantation. 2020;104(1):97-103.

115. Berzigotti A, Albillos A, Villanueva C, Genesca J, Ardevol A, Augustin S, et al. Effects of an intensive lifestyle intervention program on portal hypertension in patients with cirrhosis and obesity: the SportDiet study. Hepatology. 2017;65(4):1293-305 Only trial looking at a combined lifestyle intervention in obese patients with cirrhosis, and showing its feasibility and beneficial effect on portal pressure.

116. Macias-Rodriguez RU, Ilarraza-Lomeli H, Ruiz-Margain A, Ponce-de-Leon-Rosales S, Vargas-Vorackova F, Garcia-Flores $\mathrm{O}$, et al. Changes in hepatic venous pressure gradient induced by physical exercise in cirrhosis: results of a pilot randomized open clinical trial. Clin Transl Gastroenterol. 2016;7(7):e180.

117. Williams FR, Vallance A, Faulkner T, Towey J, Durman S, Kyte $\mathrm{D}$, et al. Home-based exercise in patients awaiting liver transplantation: a feasibility study. Liver Transpl. 2019;25(7):995-1006.

118. Chen HW, Ferrando A, White MG, Dennis RA, Xie J, Pauly M, et al. Home-based physical activity and diet intervention to improve physical function in advanced liver disease: a randomized pilot trial. Dig Dis Sci. 2020;65:3350-9.

119. Hiraoka A, Michitaka K, Kiguchi D, Izumoto H, Ueki H, Kaneto $\mathrm{M}$, et al. Efficacy of branched-chain amino acid supplementation and walking exercise for preventing sarcopenia in patients with liver cirrhosis. Eur J Gastroenterol Hepatol. 2017;29(12):141623.

120. Nishida Y, Ide Y, Okada M, Otsuka T, Eguchi Y, Ozaki I, et al. Effects of home-based exercise and branched-chain amino acid supplementation on aerobic capacity and glycemic control in patients with cirrhosis. Hepatol Res. 2017;47(3):E193-200.

121. El Sherif O, Dhaliwal A, Newsome PN, Armstrong MJ. Sarcopenia in nonalcoholic fatty liver disease: new challenges for clinical practice. Expert Rev Gastroenterol Hepatol. 2020;14(3):197-205.

122. Theodoridis X, Grammatikopoulou MG, Petalidou A, Kontonika SM, Potamianos SP, Bogdanos DP. A systematic review of medical nutrition therapy guidelines for liver cirrhosis: do we agree? Nutr Clin Pract. 2020;35(1):98-107.

123. Alavinejad P, Hajiani E, Danyaee B, Morvaridi M. The effect of nutritional education and continuous monitoring on clinical symptoms, knowledge, and quality of life in patients with cirrhosis. Gastroenterol Hepatol Bed Bench. 2019;12(1):17-24.

124. Hayward KL, Martin JH, Cottrell WN, Karmakar A, Horsfall LU, Patel PJ, et al. Patient-oriented education and medication management intervention for people with decompensated cirrhosis: study protocol for a randomized controlled trial. Trials. 2017;18(1):339.

125. Chaney AJ, Heckman MG. The benefit of supplemental nutrition education for severely malnourished patients awaiting liver transplant. Prog Transplant. 2018;28(4):390-3.

126. Ney M, Gramlich L, Mathiesen V, Bailey RJ, Haykowsky M, Ma $\mathrm{M}$, et al. Patient-perceived barriers to lifestyle interventions in cirrhosis. Saudi J Gastroenterol. 2017;23(2):97-104.

Publisher's Note Springer Nature remains neutral with regard to jurisdictional claims in published maps and institutional affiliations. 